\title{
Farklı Veri Toplama Yöntemleriyle Yapılan Hacim Hesaplamalarının Karşılaştırılması
}

\author{
Muammer SEKİ ${ }^{1 *}$, İbrahim TIRYAKİOĞLU² ${ }^{2}$, Murat UYSAL ${ }^{3}$ \\ ${ }^{1}$ Afyon Kocatepe Üniversitesi, Mühendislik Fakültesi, Harita Mühendisliği Bölümü, Afyonkarahisar \\ (muammer91@ @otmail.com) ORCID 0000-0001-8681-7756 \\ ${ }^{2}$ Afyon Kocatepe Üniversitesi, Mühendislik Fakültesi, Harita Mühendisliği Bölümü, Afyonkarahisar \\ (itiryakioglu @aku.edu.tr) ORCID 0000-0002-4954-7109 \\ ${ }^{3}$ Afyon Kocatepe Üniversitesi, Mühendislik Fakültesi, Harita Mühendisliği Bölümü, Afyonkarahisar \\ (muysal@aku.edu.tr) ORCID 0000-0001-5202-4387
}

\begin{abstract}
$\ddot{\mathbf{O z}}$
Günümüzde Harita Mühendisliğinin İnşaat ve Madencilik sektöründeki en önemli iş kollarından birisi de hacim hesabıdır. Hacim hesapları yersel ve fotogrametrik ölçüm yöntemleri kullanarak hesaplanabilmektedir. Teknolojinin gelişmesiyle birlikte fotogrametrik yöntemler de hacim hesaplarında sıkça kullanılmaya başlamıştır. Çalışmada İnsansız Hava Araçlarının günümüzde kullanım alanlarının artması göz önünde bulundurularak hacim hesaplamalarında kullanılabilirliği araştırılmıştır. Ayrıca yersel ölçümlerin farklı değerleme programları kullanılarak aynı kotlara sahip ölçülerin yazılımlar arası ne kadar değiştiğinin değerlendirilmesi de yapılmıştır. Eskişehir İli Seyitgazi ilçesinde seçilen alan Yaklaşık $18800 \mathrm{~m}^{2}$ 'dir. Bu alanda 1 ayda yaklaşık $10.000 \mathrm{~m}^{3}$ dolgu yapılmaktadır. Mayıs 2016 ve Kasım 2016 tarihlerinde yapılan yersel ölçümlere paralel olarak İnsansız hava aracı kullanılarak fotogrametrik yöntemle ölçümler de gerçekleştirilmiştir. Yersel ölçümler GPS ile yapılmıştır. İki farklı yöntemle toplanan veriler değerlendirilerek Mayıs ve Kasım ayları aralarındaki hacim farkları hesaplanmıştır. Yapılan yüzey karşılaştırmaları sonucunda fotogrametrik ölçümler ile yersel ölçümlerin arasında tutarlı sonuçlar olduğu görülmüştür. Yaklaşık 6 aylık sonuçlar incelendiğinde belirlenen alanda yersel ölçümlerde $60477.74 \mathrm{~m}^{3}$ dolgu olduğu, fotogrametrik ölçüm sonuçları incelendiğinde $61004.13 \mathrm{~m}^{3}$ dolgu sonucuna ulaşılmıştır. Yersel ve fotogrametrik ölçümler arasında $526.39 \mathrm{~m}^{3}$ fark çıkmıştır. $\mathrm{Bu}$ sonucun yersel ve fotogrametrik ölçülerin farklı günlerde yapılması ve fotogrametrik ölçümlerde arazi yüzeyinin daha detaylı temsil edilmesinden kaynaklandığı düşünülmektedir .
\end{abstract}

Anahtar Kelimeler: Hacim, gps, insansız hava arac1 (iha)

\section{Comparison of Volumes Done With Different Data Collection Methods}

\begin{abstract}
Today,Geomatics Engineering is one of the most important business lines in the construction and mining sector account for the volume. Volume calculations can be calculated using local and photogrammetric measurement methods. With the development of technology, photogrammetric methods have also been used frequently in volume calculations. In the study, the availability of unmanned aerial vehicles in volume calculations has been investigated taking into consideration the increase in the area of use today. In addition, it was also assessed how much the measurements of the geodetic measurements differed between software with the same levels using different valuation programs. Eskisehir The area selected in Illi Seyitgazi is about 18800
\end{abstract}

\footnotetext{
* Sorumlu Yazar
} 
$\mathrm{m}^{2}$. Approximately $10,000 \mathrm{~m}^{3}$ of filling is done in this area in 1 month. In parallel with the local measurements made in May 2016 and November 2016, photogrammetric measurements were also carried out using unmanned aerial vehicles. Geodetic measurements were made with GPS. The data collected by two different methods were evaluated and the volume differences between May and November were calculated. As a result of the surface comparisons made, it is seen that there are consistent results between the photogrammetric measurements and the local measurements. When the results of about 6 months were examined, it was found that $60477.74 \mathrm{~m}^{3}$ filler was determined in the field measurements and $61004.13 \mathrm{~m}^{3}$ filler result when the photogrammetric measurement results were examined. The difference between the geodetic and photogrammetric measurements was $526.39 \mathrm{~m}^{3}$. This is thought to be due to the fact that the geodetic measurements and photogrammetric measurements are made on different days and that the terrain surface is represented in more detail in photogrammetric measurements.

Keywords: Volumes, gps, unmanned aerial vehicle (uav)

\section{GİRIŞ}

Mühendislik çalışmalarında hacim hesaplamaları önemli bir yer tutmaktadır. Kazı miktarı, dolgu miktarı başta olmak üzere hacim verilerinden birçok bilgi elde edilebilmekte olup hesaplamalarında çeşitli yöntemler kullanılmaktadır. Çalışmamızda hacim hesabı uygulamalarında GPS ile yapılan yersel ölçümler ile İHA ile yapılan fotogrametrik ölçümler kıyaslanacaktır.

Farkl1 mühendislik problemlerinin çözümünde fotogrametrik tekniklerin kullanımı daha da yaygınlaşmıştır. Farklı özelliklere sahip doğal ve yapay yapıların fotogrametrik amaçlarla fotoğraflarının elde edilmesinde insansız hava araçları önemli katkılar sağlamıştır (Uysal vd., 2013a, 2013b, 2015c). Gelişen teknoloji ile birlikte günümüzde uzaktan algılama ve fotogrametri ile üretilen verilerde, üretim platformu olarak insansız hava araçları kullanılmaya başlanmıştır. Düşük maliyet, hız, yüksek çözünürlük ve tekrarlı uçuş kabiliyeti sayesinde insansız hava araçları küçük alanlar için tercih edilmektedir (Eisenbeiss, H., 2009; Changchun, L., 2010).

İnsansız Hava Araçları, günümüzde birçok farklı sektör tarafından aktif şekilde kullanılmaktadır. Özellikle son yıllarda popülerlik kazanmayı başaran İHA'lar; reklamcılıktan kargo taşımacılığına kadar farklı bir çok alanda kullanılmaktadır. Her ne kadar son yıllarda tanınmaya başlansa da İnsansız Hava Araçlarının geçmişi 20.YY'ın başlarına dayanmaktadır. (Url-1).

Günümüz gelişen teknolojisi ile otonom insansız hava araçları savunma sanayi başta olmak üzere birçok alanda yüksek bir ivme ile artan popülerliğe sahiptir. İnsansız hava araçları pazarında en büyük pay şüphesiz savunma sanayi çalışmalarınındır (Özbek, 2010).

Öncelikle savunma sanayiinde gözlem aracı olarak kullanılan İHA'lar, 20.YY'da ulaşımın zor olduğu bölgelerde analizler yapmak amacıyla tercih edilmişti. Askeri alanda kullanılmasıyla birlikte, büyük bir kitlenin dikkatini çeken İHA'lar; artık bireysel kullanımın dışında ticari amaçlı olarak da aktif şekilde tercih ediliyor.(Url-1) Ayrıca tarımsal çalışmalar, inşaat ve kültürel uygulamalar gibi çok çeşitli alanlara da yaygın olarak kullanılmaya başlamıştır (Yakar, vd. 2015).

Gelişen teknoloji ile birlikte İnsansız hava araçları birçok sektörde olduğu gibi harita sektöründe de kullanılmaya başlanmıştır. Topografik alanlarda, İnşaat sahalarında, Kübaj Hesaplamaları gibi haritacılık faaliyetlerinde kullanılabilmektedir. Yapmış olduğumuz çalışmada kübaj hesaplamalarında İHA kullanımı ve hassasiyeti üzerinde çalışılmıştır (Url-2,3).

Köroğlu (2006) da bir arazi üzerindeki değişik veri gurubu ile farklı enterpolasyon yöntemleri kullanılarak yüzey modellemesi yapılmış, bu modellerin sağladığı çözüm süreleri belirlenmiştir. Elde edilen bulguların karşı1laştırması yapılmış ve en uygun enterpolasyon stratejisi önerilen bir çalışma yapılmıştır.

Toprak (2014) de fotogrametrik teknikler ile İHA'ların mühendislik projelerinde kullanılabilirliği araştırılmıştır. Bu çalışmada 
mühendislik projelerinin daha kısa zamanda, düşük maliyetler ile daha hassas üretilebilmesi amaçlanmıştır. Çalışmada, Afyonkarahisar İli Merkezinde fotogrametrik teknikler kullanilarak, İHA ile elde edilen görüntülerden hâlihazır harita üretilmiş, hacim hesabı yapılmıştır. Yine bu çalışmada kültürel mirasların dökümantasyonu için Konya İli Beyşehir İlçesinde ve arkeolojik dökümantasyon için ise Mersin İli Silifke İlçesinde çalışmalar yapılmıştır. Bu çalışma ile İHA'ların fotogrametrik teknikler ile farklı mühendislik projelerinin yapılabilirliği gösterilmiştir.

Doğruluk (2013) de Sayısal Arazi Modeli belirlenen bir karayolu projesi için oluşturulmuştur. Farklı enterpolasyon yöntemleri (9 adet) kullanılarak sıklaştırılan yüzeyler ile proje kotlarını ifade eden yüzey arasındaki hacim hesabı yapılmıştır. Elde edilen sonuçları ile 9 farklı enterpolasyon algoritmalarının yüzeylerinin araziyi temsil etme yeteneğini etkilediği görüldüğü bir çalışma yapmıştır.

\section{YÖNTEM}

Yapmış olduğumuz çalışma Mayıs 2016 yılı ve Kasım 2016 yılları arasında yapılmıştır. Çalışma alanı olarak Eti Maden İşletmeleri Genel Müdürlüğünün Eskişehir İli Seyitgazi ilçesi Kırka beldesinde bulunan Kırka Bor İşletme Müdürlüğü'nün kil sahası tercih edilmiştir (Şekil 1).

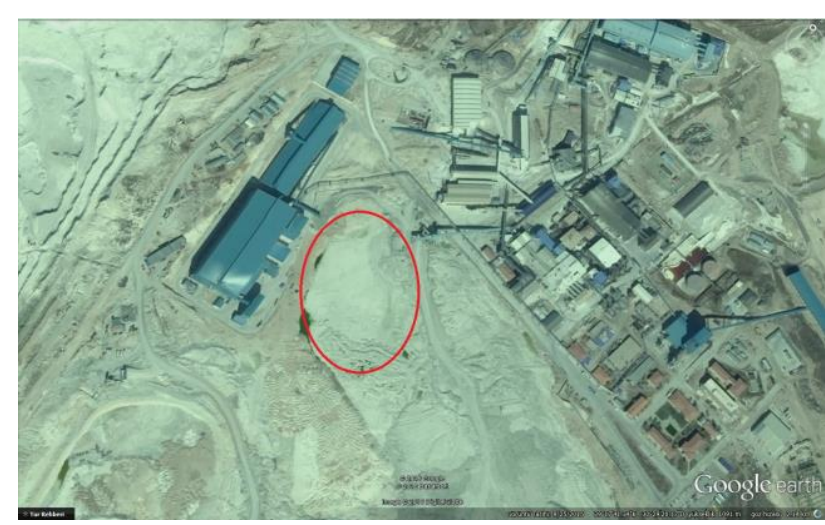

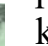

\section{Ölçüm Alanı ve Ölçüm Tarihleri}

Ölçüm yaklaşık $18.800 \mathrm{~m}^{2}$ lik alanda Tablo 1 de belirtilen günlerde yapılmıştır.

Tablo 1. Ölçüm Günleri

\begin{tabular}{lll}
\hline & Yersel & Fotogrametrik \\
\hline May1s & 30.04 .2016 & 02.05 .2016 \\
Kasim & 30.10 .2016 & 01.11 .2016 \\
\hline
\end{tabular}

Şekil 1. Çalışma Alanı 


\section{BULGULAR}

\subsection{Fotogrametrik Yöntem İle Hacim Hesabı}

Fotogrametrik Ölçümler belirtilen alanda Tablo 1 de ki tarihlerde yapılmıştır. Uçuş metresi olarak $100 \mathrm{~m}$ yükseklik seçilmiş Mayıs 2016 uçuşunda $100 \mathrm{~m}$ ' de 96 adet fotoğraf çekilmiştir. Kasım 2016 yılında ise yine $100 \mathrm{~m}$ uçuşta 204 adet fotoğraf çekilmiştir. Mayıs uçuşunda 5, Kasım uçuşunda 6 adet yer kontrol noktası işaretlenmiş ve Pix4d programında işlenmiştir.

\begin{tabular}{|c|c|c|c|c|c|c|}
\hline GCP Name & Accuracy $X Y Z[\mathrm{Z}]$ & Error $X[\mathrm{~m}]$ & Error $Y[m]$ & Error $Z[\mathrm{~m}]$ & Projection Emor [pixel] & VerifedMarked \\
\hline $1(3 \mathrm{D})$ & $0.020 / 0020$ & 0.010 & 0.008 & -0.029 & 0.712 & $6 / 6$ \\
\hline 2 (3D) & $0.020 / 0.020$ & -0.007 & 0.000 & 0.067 & 1.174 & $6 / 6$ \\
\hline $3(3 D)$ & $0.020 / 0.020$ & -0.012 & 0.041 & -0.024 & 1.799 & $7 / 7$ \\
\hline $5(3 D)$ & $0.020 / 0.020$ & 0.064 & 0.026 & -0.048 & 1210 & $6 / 6$ \\
\hline $7(3 \mathrm{D})$ & $0.020 / 0.020$ & -0.045 & -0.066 & 0.056 & 0.701 & $7 / 7$ \\
\hline $\operatorname{Mean}[\mathrm{m}]$ & & 0.001793 & 0.001826 & 0.004471 & & \\
\hline Sigma [m] & & 0.035746 & 0.036726 & 0.047605 & & \\
\hline RMS Error [m] & & 0.035791 & 0.036772 & 0.047814 & & \\
\hline
\end{tabular}

Şekil 3. Mayıs Uçuşu Pix4d Rapor Çıktısı

Fotogrametrik Ölçüm sonrasında elde edilen veriler Pix4d programında fotoğraflar birleştirilerek bir ortofoto elde edilmiş daha sonra yer kontrol noktaları işaretlenerek nokta bulutu haline dönüştürülmüştür.

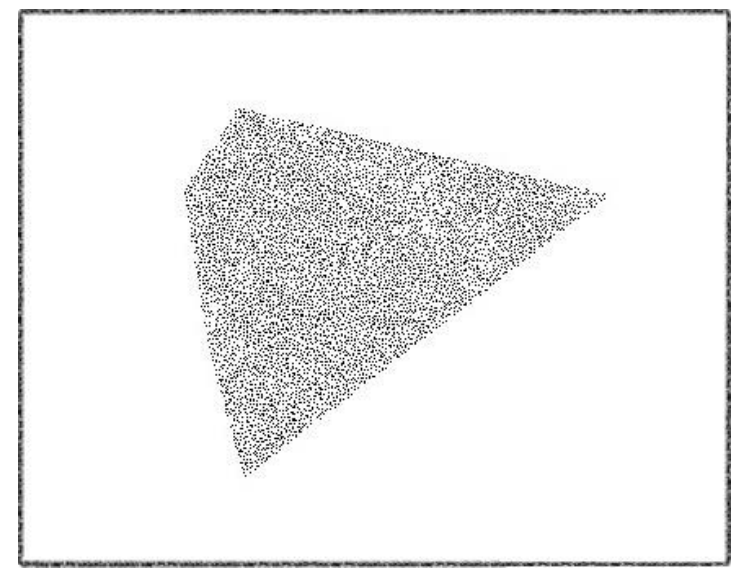

Şekil-4 Fotogrametrik Ölçüm Nokta Bulutu

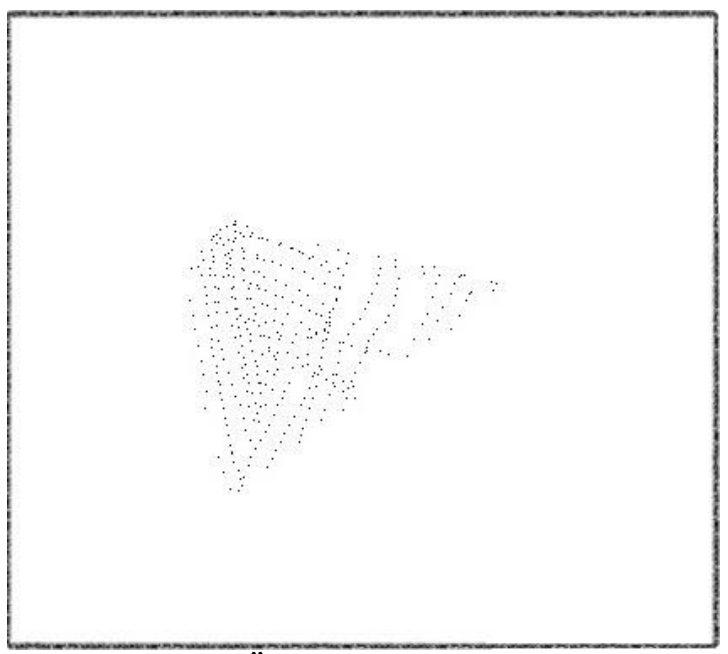

Şekil 5. Yersel Ölçüm Nokta Bulutu

Elde edilen nokta bulutları Netcad ve Eghas programının açabileceği $\mathrm{dxf}$ formatına dönüştürülüp açılmıştır. Toplamda oluşan iki nokta bulutu iki farklı programda değerlemesi yapılarak hacim değişimlerine ulaşılmıştır.

Oluşan nokta bulutları Netcad programında incelendiğinde $61335.148 \mathrm{~m}^{3}$ dolgu $408.29 \mathrm{~m}^{3}$ yarma çıkarken aynı nokta bulutu Eghas programında $61004.13 \mathrm{~m}^{3}$ dolgu $507.04 \mathrm{~m}^{3}$ yarma Microstation programında yüzeysel incelendiğinde ise $61339.6 \mathrm{~m}^{3}$ dolgu $539.9 \mathrm{~m}^{3}$ yarma sonucuna ulaşılmıştır.

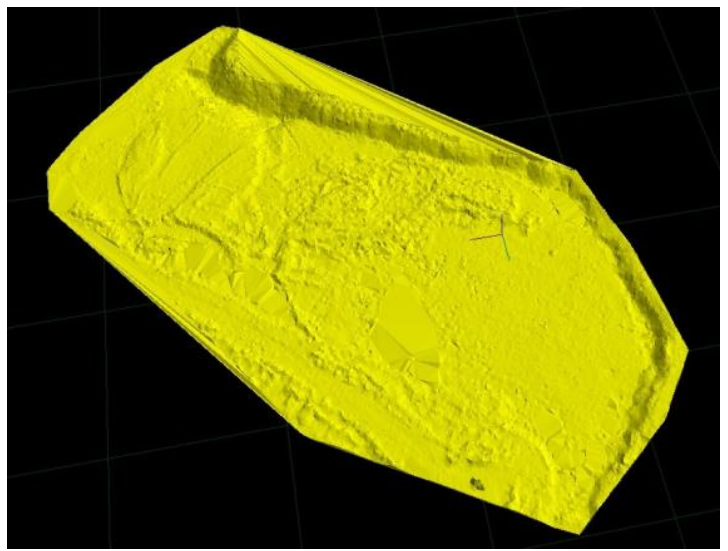

Şekil 6. Fotogrametrik Ölçüm 3B Görüntü

Fotogrametrik Ölçüm verilerinin değerlendirilmesinden çıkarılan sonuç farklı programların aynı verilerden farklı sonuç çıkarabileceği anlaşılmıştır 


\subsection{Yersel Ölçümler İle Hacim Hesabı}

Yersel ölçümler tabloda belirtildiği üzere Fotogrametrik Ölçümden bir kaç gün once işletme personeli tarafindan Spectra Sp-80 marka cihaz ile RTK yöntemiyle yapılmıştır.

Yersel ölçümler aynı Fotogrametrik Ölçümlerde olduğu gibi Netcad ve Eghas programlarında değerlendirilmiş olup Netcad programında $59650.892 \mathrm{~m}^{3}$ dolgu $18.753 \mathrm{~m}^{3}$ yarma, Eghas programinda $60477.74 \mathrm{~m}^{3}$ dolgu $104.78 \mathrm{~m}^{3}$ yarma sonucuna ulaşılmıştır. Fotogrametrik Ölçüm verilerinde olduğu gibi yersel verilerde de programlarm algoritmalarından kaynaklı farklılıklar oluşmuştur.

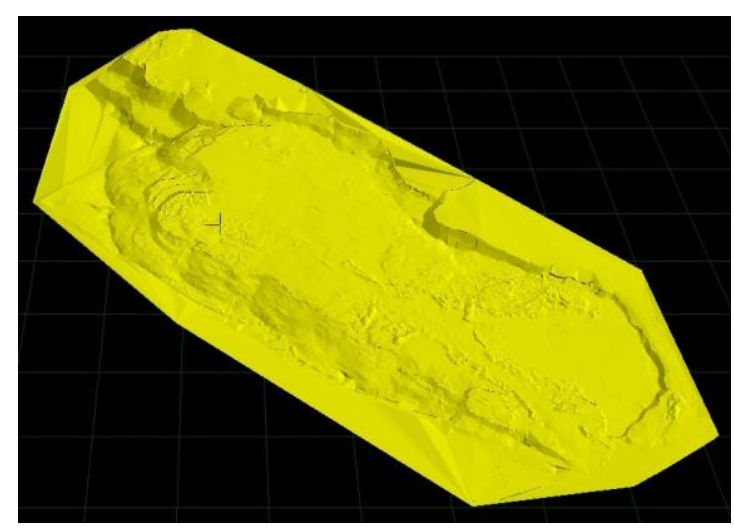

Şekil 7. Yersel Ölçüm 3B Görüntü

\subsection{Yersel Veriler ve Fotogrametrik Ölçüm Verilerinin Karşılaştırılması}

Yapılan çalışmaların sonucunda yersel veriler ve Fotogrametrik Ölçüm verileri değerlendirilip 6 aylık süreçte arazi üzerinde ne kadarlık bir hacim farklılığı olduğu sonucuna ulaşılmıştır.

Tablo 2. Eghas Hacim Değerleri

\begin{tabular}{lll}
\hline & Yersel & Fotogrametrik \\
\hline Dolgu & 60477.74 & 61004.13 \\
Yarma & 104.78 & 507.04 \\
\hline
\end{tabular}

Tablo 3. Hacim Farklılıkları

\begin{tabular}{ll}
\hline & Fark \\
\hline Dolgu & $526.39 \mathrm{~m}^{3}$ \\
Yarma & $402.26 \mathrm{~m}^{3}$ \\
\hline
\end{tabular}

Elde edilen sonuçlar üçgenleme yöntemi kullanılarak Eghas programında incelendiğinde Tablo-2 de ki sonuçlara ulaşılmıştır. Fotogrametrik Ölçüm ve yersel ölçüm arasındaki gün farkı da hesaplanarak yaklaşık olarak $191 \mathrm{~m}^{3}$ dolgu fark1 $401 \mathrm{~m}^{3}$ ise yarma farkı oluşmuştur.

İnsansız hava araçlarının yersel ölçümlere göre araziyi daha iyi temsil ettiği de hesaba katılırsa çıkan sonuçlar yersel ölçümlerle tutarlı olmuştur.

\section{SONUÇLAR ve TARTIŞMA}

İnsansız hava araçları günümüzde askeri ve sivil bir çok alanda kullanılmaya başlanmış ve bir çok alanda hem görsellik anlamında hemde bir çok iş gücünü kolaylaştırma anlamında başarılı olmuştur.

Etimaden İşletmeleri Genel Müdürlüğüne ait olan kil sahasında yapılan yersel ölçümler birden fazla kişi ile insan gücü kullanılarak çamurlu, tozlu arazi koşullarında saatlerce sürerken İHA kullanarak bir personel çok kısa sürede fotogrametrik ölçümler tamamlanmış, veri işleme ve değerleme kısmı da yapılarak sonuca ulaşılmıştır.

Sonuç olarak hem daha az maliyetli, hem de daha az iş gücü olan insansız hava araçları kullanarak yapilan hacim hesabinda zamandan çok büyük bir tasarruf sağlanmış, zorlu arazi koşullarında bile çok daha kolay ölçüm yapılması sağlanmış, arazi yüzeyi daha iyi temsil edilmiş ve değerleme sonuçlarında yersel ölçümlerle tutarlı sonuçlara ulaşılmıştır.

NOT:

Bu çalışma Afyon Kocatepe Üniversitesinde 2729 Nisan 2017 tarihleri arasında gerçekleştirilen TUFUAB IX. Teknik Sempozyumununda sunulan çalışmanın genişletilmiş ve yeniden hakemlik sürecinden geçirilerek Kabul edilmiş halidir. 


\section{TEŞEKKÜR}

Çalışmanın yapımında sağladığı desteklerden dolayı Eti Maden İşletmeleri Genel Müdürlüğü ve Kırka Bor İşletme Müdürlüğü'ne teşekkür ederiz. $\mathrm{Bu}$ çalışma AKÜ BAP tarafindan 16.FEN.BİL.24 nolu proje ile desteklenmektedir.

\section{KAYNAKÇA}

Eisenbeiss, H., 2009. UAV Photogrammetry, ETH Zurich for the degree of Doctor of Science, ISNN 0252-9335 . ISBN: 978-3906467-86-3.

Özbek,2010 “İnsansız Hava Araçlarında Farklı Kontrol Tekniklerinin Performans Karşılaştırması" Yüksek Lisans Tezi

Uysal M., Toprak A.S., Polat N., 2013a, Afyon Gedik Ahmet Paşa (İmaret) Camisinin Fotogrametrik Yöntemle Üç Boyutlu Modellenmesi, TUFUAB 2013, Trabzon.

Uysal M., Toprak A.S., Polat N., 2013b, Photo Realistic 3D Modeling with UAV: Gedik Ahmet Pasha Mosque in Afyonkarahisar, CIPA 2013 Symposium, 3-6 September 2013,659-662

Uysal M., Toprak A.S., Polat N. İnsansız Hava Araçları İle Sayısal Arazi Modeli Üretimi, TUFUAB 2015

Yakar M., Toprak A.S., Ulvi A., Uysal M. Konya Beyşehir Bezariye Hanının (bedesten) İha ile Fotogrametrik Teknik Kullanılarak Üç Boyutlu Modellenmesi

Köroğlu, S. (2006). Farklı enterpolasyon yöntemlerinin hacim hesabına etkisinin araştırılması, Yüksek Lisans Tezi.

Doğruluk, M. (2013). Sayısal arazi modellerinin karayolu projelerindeki hacim hesaplamalarına etkisi, Yüksek Lisans Tezi.

Toprak, A.S. (2014). Fotogrametrik tekniklerin insansız hava araçları ile mühendislik projelerinde kullanılabilirliğinin araştırılması, Yüksek Lisans Tezi.

Url-1:www.gzt.com/teknoloji/drone-nedir-vehangi-alanlarda-kullanilir-2576541
Url-2:http://www.deltalidar.com/Drone-IleHaritalama.aspx

Url-3:https://www.kentharita.com/drone-kullanimalanlari-nelerdir/drone-kullanim-alanlari/

Url-4:http://store.dji.com/product/phantom-3professional / 